\title{
Fluorescence spectroscopy as a tool for determination of organic matter removal efficiency at water treatment works
}

\author{
M. Z. Bieroza ${ }^{1}$, J. Bridgeman ${ }^{1}$, and A. Baker ${ }^{2}$ \\ ${ }^{1}$ School of Civil Engineering, University of Birmingham, UK \\ ${ }^{2}$ School of Geography, Earth and Environmental Sciences, University of Birmingham, UK \\ Received: 11 December 2009 - Published in Drink. Water Eng. Sci. Discuss.: 23 December 2009 \\ Revised: 18 March 2010 - Accepted: 30 March 2010 - Published: 29 April 2010
}

\begin{abstract}
Organic matter $(\mathrm{OM})$ in drinking water treatment is a common impediment responsible for increased coagulant and disinfectant dosages, formation of carcinogenic disinfection-by products, and microbial re-growth in distribution system. The inherent heterogeneity of OM implies the utilization of advanced analytical techniques for its characterization and assessment of removal efficiency. Here, the application of simple fluorescence excitation-emission technique to $\mathrm{OM}$ characterization in drinking water treatment is presented. The fluorescence data of raw and clarified water was obtained from 16 drinking water treatment works. The reduction in fulvic-like fluorescence was found to significantly correlate with OM removal measured with total organic carbon (TOC). Fluorescence properties, fulvic- and tryptophan-like regions, were found to discriminate OM fractions of different removal efficiencies. The results obtained in the study show that fluorescence spectroscopy provides a rapid and accurate characterization and quantification of OM fractions and indication of their treatability in conventional water treatment.
\end{abstract}

\section{Introduction}

In surface waters, dissolved organic matter (DOM) is an important compound comprising naturally occurring freshwater DOM (mainly humic fraction) and a heterogeneous mixture of DOM from domestic and industrial waste (fulvic acids, proteins, carbohydrates and lipids).

In drinking water treatment DOM interferes with most of the treatment processes. DOM is responsible for unpleasant odour and taste in water, formation of carcinogenic disinfection by-products (DBPs) such as trihalomethanes (THMs) and haloacetic acids (HAAs), fouling of filtration membranes, increased disinfectant demands and microbial regrowth in the distribution system. Thus, the main focus in water treatment studies has been on improving the organic matter removal efficiency (i.e. enhanced coagulation, ultraviolet (UV) irradiation, membrane filtration, ion exchange) and development of novel techniques of DOM characterization.

Correspondence to: M. Z. Bieroza

(magdalena.bieroza@gmail.com)
The heterogeneous organic matter character complicates the identification and quantification of its structure and functionality. Differences in elemental composition, charge, and secondary and tertiary structure of various organic matter compounds influence their functionality, reactivity and treatability. Aromatic structures of the humic substances containing phenolic functional groups (hydroxyl-, carboxy-, and methoxy-substituted aromatic units) have been reported to be highly reactive with chlorine in producing DBPs (Reckhow et al., 1990; Korshin et al., 1999; Wu et al., 2003; Soh et al., 2008). However, during the conventional treatment by coagulation, the hydrophobic and high molecular weight fraction of humic OM is preferentially removed. Thus, the effective removal of aromatic OM prior to disinfection with chlorine significantly reduces DBPs formation potential. The opposite reactivity and removal efficiency can be ascribed to hydrophilic OM fraction, which comprises lower molecular weight autochthonous material. Hydrophilic fraction is in general recalcitrant to coagulation removal, significantly contributes to biodegradable OM responsible for biofilm formation in the distribution system, and is the major precursor of HAAs (Kim and Yu, 2005; Soh et al., 2008). 
Different isolation and fractionation techniques have been used to characterize DOM removal and relate it with OM reactivity. Resin fractionation has become the most common method to characterize organic matter in drinking water treatment. It involves the separation of OM into its humic/non-humic and hydrophobic/hydrophilic fractions (Leenheer, 1981; Chow et al., 2004; Soh et al., 2008). Furthermore, the molecular size distribution of OM determined by high-performance size exclusion chromatography (HPSEC) has been related to OM removal efficiency and DBPs formation potential (Her et al., 2002).

However, the applicability of the isolation techniques in the assessment of OM in drinking water treatment can be limited due to time-consuming preparation and laboratory analysis, distinctive alterations to water samples (i.e. $\mathrm{pH}$ ) and question of representation of raw water properties by obtained fractions (Kitis et al., 2001; Rosario-Ortiz et al., 2007). Thus, to quantify the overall OM concentration and its reactivity in DBPs formation of bulk water samples, the application of easily measured surrogate parameters has been investigated. Two analytical methods have been commonly available to determine the OM content in water, TOC and UV absorbance measured at $254 \mathrm{~nm}$ or $272 \mathrm{~nm}$.

TOC is commonly used as a measure of a water treatment performance and, in particular, of THMs precursor material. A relationship between UV absorbance at $254 \mathrm{~nm}$ and DBPs formation potential is well established (Wu et al., 2000). UV absorbance has been reported to be more sensitive and accurate surrogate parameter for predicting the OM reactivity than TOC (Najm et al., 1994; Roccaro and Vagliasindi, 2009). Specific ultraviolet absorbance (SUVA, the absorbance at $254 \mathrm{~nm}$ per unit of dissolved organic carbon (DOC in $\mathrm{mg} / \mathrm{l}$ ) has been found to be a good indicator of aromatic carbon content, however the critique of this method is also found in literature (Weishaar et al., 2003; Ates et al., 2007). Differential UV spectroscopy has been utilized in characterization of the reaction between organic matter and disinfectants and correlated with the total organic halogen (TOX) formation (Li et al., 2000; Wu et al., 2003; Roccaro and Vagliasindi, 2009).

The main limitation of UV absorbance techniques in OM characterization in water treatment includes the interference from UV absorbing compounds present in water (turbidity, inorganic substances like nitrate nitrogen) (Eaton, 1995; Wang and Hsieh, 2001). Moreover, the relationship between UV absorbance surrogates and DBPs formation potential is dependent on the site-specific OM properties and impedes the direct comparison of the samples derived from various locations.

From the above comparison of available methods of OM removal/DBPs formation potential assessment it can be seen that the analysis of water samples under ambient conditions ( $\mathrm{pH}$, ionic strength, concentration), high instrumental sensitivity and minimal, non-destructive sample pre-treatment is of the greatest importance.
Fluorescence spectroscopy technique is becoming an increasingly popular method in DOM studies and can facilitate rapid, accurate and on-line OM prediction. DOM in surface and ground waters exhibits distinctive fluorescence properties as a result of absorption of high-energy photons by an organic matter molecule and re-emission of lower-energy photons at longer wavelengths. This inherent spectral property can be utilized in fingerprinting of DOM with fluorescence spectroscopy technique. The main applications of fluorescence spectroscopy include the characterization of DOM composition and sources and determination of the general water quality. The method is non-invasive, rapid and accurate with potential for online monitoring (Baker, 2001; Her et al., 2003).

Previous applications of fluorescence technique in water treatment include studies of OM reactivity with disinfectant (Korshin et al., 1999; Świetlik and Sikorska, 2004), prediction of THMs formation (Beggs et al., 2009), and more recently correlation of fluorescence properties with SUVA and DBPs formation during chloramination (Yang et al., 2008), and OM characterization in membrane permeates (Peiris et al., 2008). Her et al. (2003) demonstrated combined HPSECfluorescence approach for DOM characterization in bulk water samples without fractionation.

Fluorescence fulvic- and humic-like regions can be attributed to natural, allochthonous sources of organic matter (e.g. derived from the decomposition of plant tissues), whereas tryptophan-like fluorescence indicates presence of labile, microbial derived organic matter including anthropogenic pollution (Nguyen et al., 2005; Hudson et al., 2008). Thus, tryptophan-like fluorescence can be related to biological oxygen demand (Hudson et al., 2008). Fulvic-like fluorescence intensity has been demonstrated to correlate with TOC concentration, whereas its emission wavelength correlates with organic matter aromaticity and hydrophobicity (Kalbitz et al., 1999; Cumberland and Baker, 2001; Hudson et al., 2007; Baker et al., 2008). Fulvic-like fluorescence intensity per unit absorbance at $340 \mathrm{~nm}$ is known to correlate with molecular weight (Stewart and Wetzel, 1980).

In this project, the application of excitation emission matrix fluorescence spectroscopy (EEMs) to assess OM removal and formation of DBPs at water treatment works (WTW) is being investigated. EEMs offer a rapid indication of OM properties and DOM removal from water and hence possibly a useful process assessment and optimization tool at water treatment works. To date, application of fluorescence spectroscopy for characterization of OM properties and its removal efficiency in drinking water treatment has been limited. This paper demonstrates novel application of the EEMs technique for quantitative and qualitative characterization of $\mathrm{OM}$ and DBPs precursor removal during the coagulation stage. 


\section{Materials and methods}

\subsection{Sample sites}

Fluorescence spectroscopy measurements and TOC analyses were carried out on samples of raw and clarified water from 16 surface WTWs, collected monthly between August 2006 and February 2008. In order to reveal the relative change in fluorescence properties, and hence organic matter removal across different treatment stages additional sampling was carried out on selected WTWs. Here, fluorescence properties across WTW were reported for site 13, exhibiting intermediate $\mathrm{OM}$ character in terms of hydrophobicity and moderate OM removal.

The treatment works are located in the Midlands region, central UK and are owned and operated by Severn Trent Water Ltd. The WTWs treat a range of raw waters from upland sources with natural organic matter of high TOC concentrations to lowland sources reflecting anthropogenicallyimpacted microbial organic matter character. Variation in recharge, land cover patterns and anthropogenic impacts on particular catchments produce variation in OM character (relative proportion of hydrophobic/hydrophilic fractions) between WTWs and hence influence their efficiency in OM removal. As a result, a significant spatial and temporal variation in raw water OM properties (measured as fluorescence, UV absorbance and TOC parameters) was observed in the study period. Typically, the treatment works contain coagulation with ferric sulphate, dissolved air flotation, deep bed filtration, and granular activated carbon adsorption prior to chlorination. During the course of this investigation, the works' performance did not undergo any significant changes as indicated by only minor variations in treatment parameters (coagulant dose, clarification $\mathrm{pH}$, final water chlorine residual and final water $\mathrm{pH}$ ).

\subsection{Analytical methods}

Each month, raw and clarified water samples were collected from the 16 WTWs. Prior to all laboratory analyses (fluorescence, TOC and UV) samples were stored cool and in the dark between three and seven days from collection. Storage test experiments were undertaken to demonstrate that degradation of water samples was insignificant under these storage conditions (Bieroza et al., 2009). In fluorescence EEM technique fluorescence intensity of water sample is scanned over the range of excitation and emission wavelengths to produce three-dimensional matrix (Fig. 1). Fluorescent OM exhibits discrete intensity peaks located at different excitationemission wavelengths. Therefore, the presence and relative concentration of particular fluorophores (fluorescent organic matter fractions) can be derived from EEM. For all water samples in the study, the presence of three main fluorescence peak regions was observed: fulvic-like fluorescence (peak C, fluorescence excited between 300 and $340 \mathrm{~nm}$, and emitted

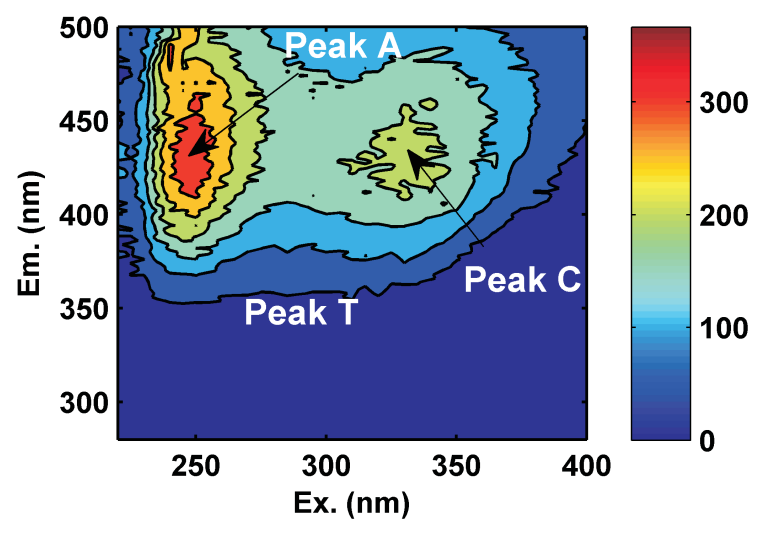

Figure 1. Fluorescence EEM of raw water. Fluorescence regions: fulvic-like fluorescence (Peak C), humic-like fluorescence (Peak A), tryptophan-like fluorescence (Peak T).

between 400 and $460 \mathrm{~nm}$ ), humic-like fluorescence (peak A, fluorescence excited between 220 and $250 \mathrm{~nm}$, and emitted between 400 and $460 \mathrm{~nm}$ ), and tryptophan-like fluorescence (peak T, fluorescence excited between 270 and $280 \mathrm{~nm}$ and emitted between 330 and $370 \mathrm{~nm}$ ) (Coble, 1996).

Laboratory analytical methods have been presented in detail previously (Bieroza et al., 2009). In summary, fluorescence EEMs were collected using a Cary Eclipse Fluorescence Spectrophotometer (Varian, Surrey, UK) equipped with a Peltier temperature controller. For each unfiltered water sample, the fluorescence was measured in duplicate by scanning the excitation wavelengths from 200 to $400 \mathrm{~nm}$ in $5 \mathrm{~nm}$ steps, and detecting the emission intensity in $2 \mathrm{~nm}$ steps between 280 and $500 \mathrm{~nm}$. Excitation and emission slit widths were $5 \mathrm{~nm}$. Each measurement was carried out in standard quartz $4 \mathrm{~cm}^{3}$ capacity cuvette $(1.0 \mathrm{~cm}$ path length) and was completed within $2 \mathrm{~min}$. To maintain the consistency of measurements and standardise the fluorescence data, all fluorescence intensities were corrected to Raman peak intensity of 20 units measured for deionised water at $348 \mathrm{~nm}$ excitation and $396 \mathrm{~nm}$ emission wavelengths (Baker, 2001). Fluorescence regions of EEM containing redundant information were removed (i.e. the Rayleigh and Raman scatter regions) prior to further data analyses.

TOC was measured using a Shimadzu TOC-V-CSH analyser with auto-sampler TOC-ASI-V. The non-purgable organic carbon (NPOC) method was employed to determine TOC (organic carbon remaining in an acidified sample after purging the sample with gas). The result TOC was calculated as a mean of the three valid measurements.

UV absorbance was measured in duplicate with the WPA Lightwave UV-VIS spectrometer between 200 and $800 \mathrm{~nm}$ with deionised water as the blank. A quartz cuvette with $1.0 \mathrm{~cm}$ path length was used. 


\section{Results and discussion}

\subsection{Fluorescence through water treatment works}

The relative change in quantitative and qualitative properties of EEMs collected for different water treatment stages can provide useful information on the degree of OM removal with relation to physicochemical properties of the removed fractions. Here, fluorescence analysis was carried out on raw, clarified, filtered, post granular activated carbon (GAC) water, pre-contact tank, post contact tank pre de-chlorination, post contact tank post de-chlorination, and final water samples. In Fig. 2 fluorescence EEMs of raw, post-clarification, post-GAC, and final water were shown. The fluorescence intensities in all three fluorescence peak regions were substantially decreased across WTW, especially within the areas of the highest initial fluorescence intensity (humic-like and fulvic-like). The relative reduction in $\mathrm{OM}$ measured as a peak $\mathrm{C}$ intensity between raw water and subsequent treatment stages increased from $25 \%$ for post-clarification, to $64 \%$ for post-GAC, and to $70 \%$ for final water. However, the highest OM removal was observed for pre-contact tank stage ( $80 \%$ of initial raw water peak C intensity). Similar pattern of changes was observed for other WTWs however the degree of OM removal at particular treatment stages was depended on site-specific OM properties and utilized treatment processes (data not presented here).

The OM removal throughout the water treatment is accompanied with the changes in structural and chemical OM properties. Here, the relative position of the maximum peak $\mathrm{C}$ fluorescence intensity was shifted towards lower emission wavelengths indicating the reduction in the degree of aromaticity of residual OM fraction. Thus, the more aromatic, higher molecular weight OM constituents are preferentially removed prior to disinfection stage of water treatment.

During the chlorination due to chlorine/OM reactions, the fluorescence signature becomes more equivocal, and both increases and decreases in fluorescence intensity can be discerned. Depending on the primary reaction pathway (substitution or oxidation), type and amount of intermediate chlorination species generated, different functional groups are selectively transformed and removed. During halogenation a common selective removal of high molecular weight, highly conjugated aromatic structures containing carbonyl, hydroxyl and amine functional groups occur (Senesi, 1990). As a result of breakdown of active aromatic structures in humic molecules into smaller compounds, the fluorescence intensity increases particularly in tryptophan and peak $\mathrm{C}$ of lower emission wavelength regions (Korshin et al., 1999; Świetlik and Sikorska, 2004). This can explain the higher fluorescence intensities for final water stage compared with chlorination stage observed here (Table 1). Moreover, the depletion of chlorine residual post-chlorination enhances the microbial activity and results in higher amounts of autochthonous $\mathrm{OM}$ ascribed to tryptophan-like fluorescence.
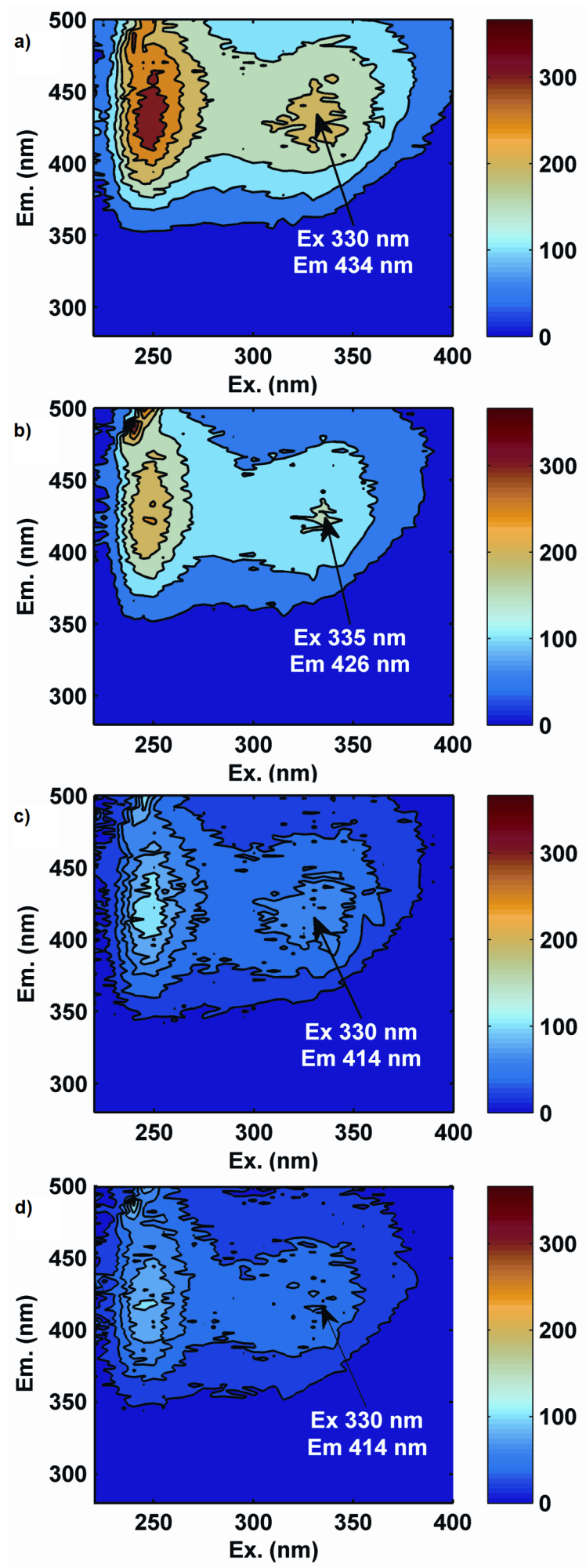

Figure 2. Fluorescence EEMs of raw (a), post-clarification (b), post-GAC (c), and final water (d) at site 13 collected on $5 \mathrm{Au}-$ gust 2007. The location of peak $\mathrm{C}$ fluorescence maximum indicated with arrow. Fluorescence emission intensity in arbitrary units. 
Table 1. Excitation-emission matrices of raw (1), clarified (2), filtered (3), post-GAC water (4), pre-contact tank (5), post contact tank pre de-chlorination (6), post contact tank post de-chlorination (7), and final water (8). Site 13, 05.08.07.

\begin{tabular}{cccc|ccc|c}
\hline \multirow{3}{*}{ Sample } & \multicolumn{3}{c|}{ Peak A } & \multicolumn{3}{c|}{ Peak C } & Peak T \\
\cline { 2 - 8 } & $\begin{array}{c}\text { Emission } \\
\text { wavelength } \\
(\mathrm{nm})\end{array}$ & $\begin{array}{c}\text { Excitation } \\
\text { wavelength } \\
(\mathrm{nm})\end{array}$ & $\begin{array}{c}\text { Intensity } \\
(\mathrm{au})\end{array}$ & $\begin{array}{c}\text { Emission } \\
\text { wavelength } \\
(\mathrm{nm})\end{array}$ & $\begin{array}{c}\text { Excitation } \\
\text { wavelength } \\
(\mathrm{nm})\end{array}$ & $\begin{array}{c}\text { Intensity } \\
(\mathrm{au})\end{array}$ & $\begin{array}{c}\text { Intensity } \\
(\mathrm{au})\end{array}$ \\
\hline 1 & 430 & 250 & 347.9 & 432 & 340 & 228.9 & 37.7 \\
2 & 422 & 250 & 264.2 & 422 & 340 & 165.3 & 31.7 \\
3 & 428 & 255 & 191.8 & 424 & 340 & 149.3 & 26.2 \\
4 & 422 & 250 & 120.4 & 422 & 325 & 81.9 & 21.0 \\
5 & 424 & 235 & 115.2 & 424 & 340 & 45.2 & 5.4 \\
6 & 414 & 254 & 84.7 & 412 & 320 & 49.5 & 10.9 \\
7 & 406 & 250 & 115.8 & 408 & 315 & 62.5 & 15.0 \\
8 & 416 & 245 & 106.1 & 416 & 335 & 64.7 & 16.5 \\
\hline
\end{tabular}

\subsection{OM characterization with fluorescence EEM}

The decrease in TOC (NPOC) concentration between raw and clarified water was used to assess the OM removal efficiency at 16 WTWs. Previous studies showed that the peak C intensity correlates with TOC (Hudson et al., 2007). Here, for each WTW, OM removal was calculated from the decrease in organic matter fluorescence intensity of peak $\mathrm{C}$ between raw and clarified water samples and compared with actual reduction in TOC concentrations. A strong, linear correlation was observed between fluorescence-derived and TOC-measured OM removal between raw and clarified water with the correlation coefficient $R^{2}=0.90$ (Fig. 4). The relationship was developed on the basis of fluorescence data obtained for all sample sites and thus enables direct comparison of the OM removal efficiency between different WTWs.

The efficiency of organic matter removal by coagulation depends on both quantitative and qualitative organic matter properties. Higher OM removal in percentage terms is observed for samples with moderate and high organic matter concentrations (Soh et al., 2008), what can be observed in this study e.g. for site 1 . Higher TOC concentrations correlate with higher contribution of humic substances, preferentially removed by coagulation due to their high molecular weights.

The differences in organic matter properties (molecular weight, aromaticity, hydrophobicity, presence of particular functional groups) determine the varying impact of coagulation processes on removal of different organic matter fractions. The higher removal efficiencies occur for the high molecular-weighted aromatic humic substances, of greater THM formation potential and greater affinity for hydrophobic compounds.

Figure 3 presents the relationship between TOC removal across coagulation treatment stage and fluorescence properties of raw water.

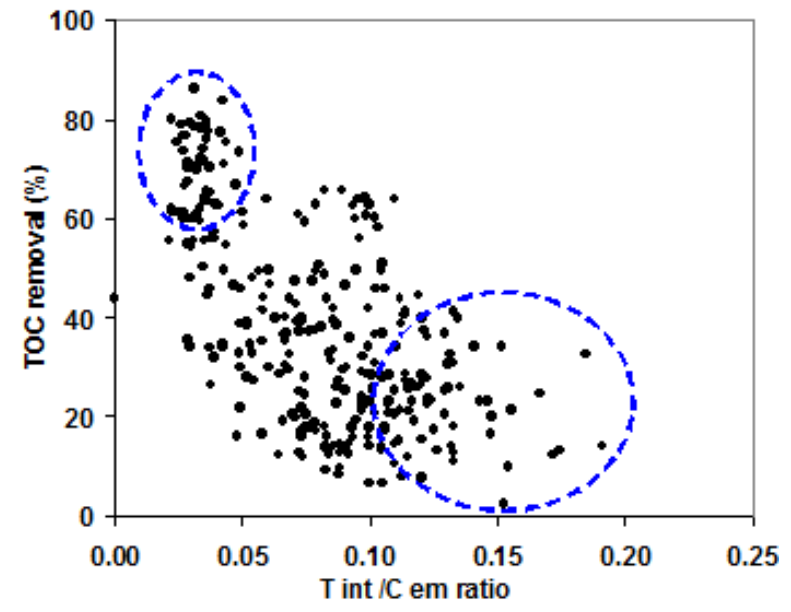

Figure 3. Peak $\mathrm{T}$ intensity/ peak $\mathrm{C}$ emission wavelength ratio vs. TOC removal efficiency. Circles indicate two fluorescence endmembers.

Peak C emission wavelength and tryptophan-like fluorescence intensity were found to provide the best discrimination between sample sites. It can be observed that the efficiency of OM removal is dependent on the presence of two fluorescence end-members, of high peak $\mathrm{C}$ emission and low tryptophan-like fluorescence (low $\mathrm{T}$ int/C em), and of low peak $\mathrm{C}$ emission and high tryptophan-like content (high $\mathrm{T}$ int/C em). The first group of fluorophores comprises higher content of aromatic structures and low fraction of the hydrophilic microbially-derived material. Thus, the overall OM removal by coagulation in the samples with predominant allochthonous aromatic OM is high and the THM formation potential is significantly reduced. The highest removal of $70-80 \%$ exhibits site 1 , where the naturally low raw water $\mathrm{pH}$ enhances the OM removal by coagulation.

High tryptophan-like fluorescence intensity correlates with low peak $\mathrm{C}$ emission wavelength and indicates the 
predominance of hydrophilic, autochthonous low molecular material, recalcitrant to removal by coagulation. This fraction was reported to significantly contribute to the formation of DBPs and biodegradable DOM (Soh et al., 2008). Although the THM formation potential of hydrophilic fraction is distinctively lower than of hydrophobic OM, the intrinsic poor removal of the former by coagulation produces substantial amount of THMs precursors prior to halogenation. Therefore, for sites with the lowest TOC removal of 20-30\%, additional treatment of residual hydrophilic DOM is required (i.e. GAC or membrane filtration).

\subsection{OM removal prediction}

Based on the results presented in the literature it can be noticed that the OM removal between raw and clarified water denotes the removal of the hydrophobic fraction of the highest THM formation potential by coagulation. It also demonstrates the residual content of hydrophilic fraction that is more recalcitrant to coagulation removal and therefore should be effectively removed prior to disinfection stage using different techniques (i.e. GAC). Thus, rapid indication of the OM removal between raw and clarified water with fluorescence technique can serve as a real-time monitoring tool for the assessment of the DBPs formation potential.

The efficiency of OM removal prediction with fluorescence EEM technique was compared with the linear regression model developed from the UV absorbance at $254 \mathrm{~nm}$ measurements between raw and clarified water (Fig. 4). The decrease in absorbance in percentage terms was plotted against the TOC removal, however a poorer correlation (coefficient value of $R^{2}=0.69$ ) was obtained compared with the fluorescence-derived model. As both techniques measure the spectral properties of OM, there is a significant difference in the intrinsic OM properties determined with fluorescence and UV absorbance (Yang et al., 2008). The highest absorptivities are pertinent to aromatic OM structures, however the fluorescence intensities of aromatic fraction are dependent on the composition of functional groups in molecules. For electron-donating groups including hydroxyl and amine higher fluorescence intensities are observed, whereas lower can be ascribed to electron-withdrawing functional groups (i.e. carboxylic) (Świetlik and Sikorska, 2004). Thus, fluorescence provides better ability to characterize bulk OM properties as demonstrated here in better correlation between TOC and OM removal calculated from fluorescence properties.

Additionally, two simple linear regression models of OM removal by coagulation were developed and validated on the independent fluorescence data:

TOCrem $(\%)=-206.71-0.68 \mathrm{~T}_{\text {intRAW }}+0.52 \mathrm{C}_{\text {emRAW }}+0.11 \mathrm{C}_{\text {intRAW }}$

(Raw)

$\operatorname{TOCrem}(\%)=-62.77-0.15 \mathrm{~T}_{\text {intCLA }}+0.24 \mathrm{C}_{\text {emRAW }}+0.26 \mathrm{C}_{\text {intRAW }}-0.40 \mathrm{C}_{\text {intCLA }}$
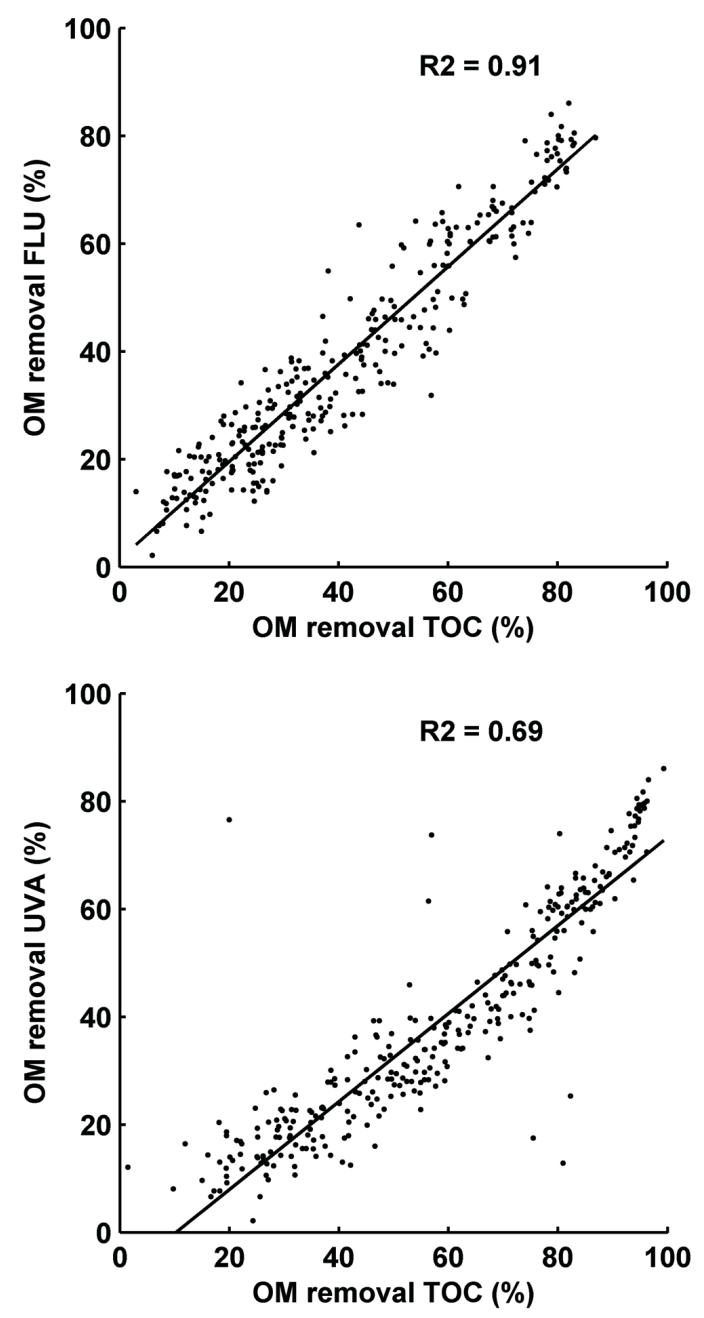

Figure 4. OM removal prediction with differential fluorescence (OM removal FLU) and differential UVA (OM removal UVA) between raw and clarified water.

where: $\mathrm{T}_{\mathrm{int}}-$ tryptophan-like fluorescence intensity, $\mathrm{C}_{\mathrm{em}}-$ peak $\mathrm{C}$ emission wavelength, and $\mathrm{C}_{\mathrm{int}}$ - and peak $\mathrm{C}$ fluorescence intensity.

In both models, fluorescence properties characterizing OM matter were incorporated, peak $\mathrm{C}$ emission wavelength (surrogate for the degree of aromaticity), and tryptophan-like fluorescence intensity (surrogate for microbial fraction content). The first model (Raw FLU) based on solely raw water fluorescence properties appeared to be less robust compared with the second model (Raw\&Cla FLU) incorporating both raw and clarified water fluorescence variables (correlation coefficient values of $R^{2}=0.55$ and $R^{2}=0.86$ respectively). The results of the independent validation tests showed good agreement between actual OM removal and predicted with the second fluorescence model (on average $95 \%$ of data variance was explained by the model). 


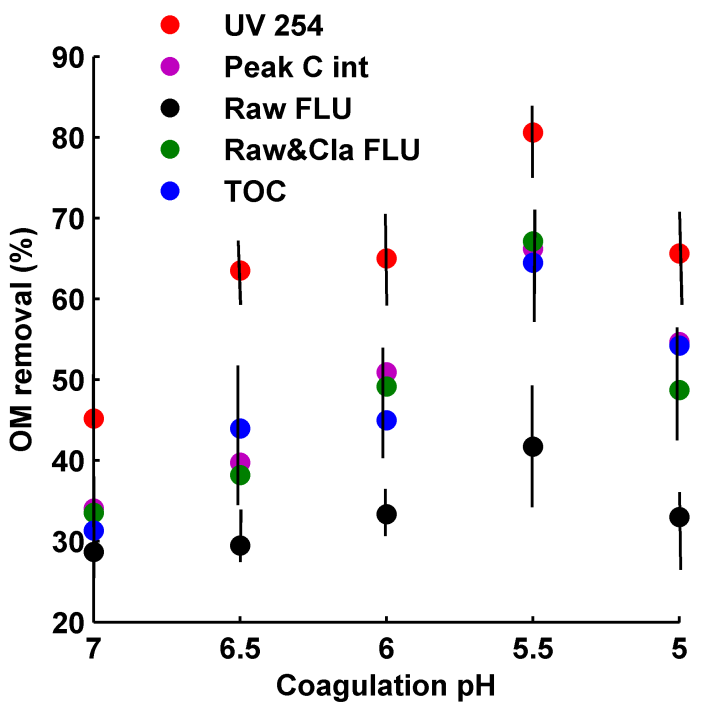

Figure 5. OM removal between raw and clarified water vs. coagulation $\mathrm{pH}$ (site 2).

The efficacy of previously developed fluorescence models of OM removal prediction was also tested with the fluorescence data collected during the coagulation optimization trial at site 3 (Bieroza et al., 2010). In the experiment the coagulation $\mathrm{pH}$ was lowered from the baseline $\mathrm{pH} 7.0$ to $\mathrm{pH} 5.0$ and the increase in OM removal measured as a reduction in TOC between raw and clarified stage was observed from $34.0 \%$ to $66.2 \%$ (Fig. 5). These results were found to be in accordance with the prediction based on the reduction in peak $\mathrm{C}$ intensity. With lowering coagulation $\mathrm{pH}$ the Raw FLU models performance was found to gradually deteriorate compared with TOC removal results. In the experiment, the OM removal improvement was simply the result of optimized treatment conditions, without corresponding changes in raw water OM character. Thus, the Raw FLU model demonstrates the baseline OM removal efficiency for the predominant type of OM for not optimized WTW. The Raw\&Cla FLU model produced consistent results with actual OM removal, as based on differential fluorescence OM properties between raw and clarified water.

\section{Conclusions}

Fluorescence EEM technique can be successfully utilized in drinking water treatment for rapid, accurate, and comprehensive characterization of organic matter. Here, the fluorescence analysis across the WTW enabled qualitative characterization of the OM fractions preferentially removed by subsequent treatment processes. Fluorescence properties, peak $\mathrm{C}$ emission wavelength and tryptophan-like fluorescence can describe OM properties in terms of degree of aromaticity and content of microbial DOM respectively (Baker et al., 2008).. Here, the correlations between peak C, tryptophan- like fluorescence and TOC removal were tested. For sites with high peak $\mathrm{C}$ emission wavelength and low tryptophanlike fluorescence, the OM removal efficiency was the highest and therefore the potential DBPs formation significantly reduced. These fluorescence properties are pertinent to highly aromatic, high molecular weight $\mathrm{OM}$ fraction that is easier to remove by conventional coagulation process. The reduction in peak $\mathrm{C}$ intensity between raw and clarified water strongly correlated with OM removal measured as a TOC reduction. Fluorescence peak $\mathrm{C}$ provided better prediction of OM removal across coagulation compared with UV absorbance at $254 \mathrm{~nm}$. Moreover, two fluorescence-derived models of OM removal were developed and tested for independent fluorescence dataset. The model incorporating tryptophan-like fluorescence intensity of clarified water, peak $\mathrm{C}$ emission wavelength of raw water, and peak $\mathrm{C}$ intensities of raw and clarified water provided a good agreement with actual OM removal data for operational and changing treatment conditions (coagulation optimization).

Edited by: I. Worm

\section{References}

Ates, N., Yetis, U., and Kitis, M.: Effects of bromide ion and natural organic matter fractions on the formation and speciation of chlorination by-products, J. Environ. Eng., 133(10), 947-954, 2007.

Baker, A., Tipping, E., Thacker, S. A., and Gondar, D.: Relating dissolved organic matter fluorescence and functional properties, Chemosphere, 73, 1765-1772, 2008.

Beggs, K. M. H., Summers, R. S., and McKnight, D. M.: Characterizing chlorine oxidation of dissolved organic matter and disinfection by-product formation with fluorescence spectroscopy and parallel factor analysis, J. Geophys. Res.-Bio., 114, G04001, doi:10.1029/2009JG001009, 2009.

Bieroza, M., Baker, A., and Bridgeman, J.: Relating freshwater organic matter fluorescence to organic carbon removal efficiency in drinking water treatment, Environ. Sci. Technol., 407, 17651774, 2009.

Bieroza, M., Baker, A., and Bridgeman, J.: An assessment of low $\mathrm{pH}$ coagulation performance using fluorescence spectroscopy, J. Environ. Eng.-ASCE, submitted, 2010.

Chow, C. W. K., Fabris, R., and Drikas, M.: A rapid fractionation technique to characterise natural organic matter for the optimisation of water treatment processes, J. Water Supply Res. Technol.AQUA, 53(2), 85-92, 2004.

Coble, P.G.: Characterization of marine and terrestrial DOM in seawater usingexcitatio n-emission matrix spectroscopy, Mar. Chem., 51, 325-346, 1996.

Cumberland, S. A. and Baker, A.: The freshwater dissolved organic matter fluorescence-total organic carbon relationship, Hydrol. Process., 21(16), 2093-2099, 2007.

Eaton, A.: Measuring UV-absorbing organics: a standard method, J. Amer. Water Works Assoc., 87, 86-90, 1995.

Hudson, N. J., Baker, A., and Reynolds, D.: Fluorescence analysis of dissolved organic matter in natural, waste and polluted waters - a review, River Res. Appl., 23(6), 631-649, 2007. 
Hudson, N. J., Baker, A., and Ward, D.: Fluorescence spectrometry as a surrogate for the BOD5 test in water quality assessment: an example from South West England, Sci. Total Environ., 391(1), 149-158, 2008.

Her, N., Amy, G., Foss, D., and Cho, J.: Variations of molecular weight estimation by HP-Size Exclusion Chromatography with UVA versus online DOC detection, Environ. Sci. Technol., 36, 3393-3399, 2002.

Her, N., Amy, G., McKnight, D., et al.: Characterization of DOM as a function of MW by fluorescence EEM and HPLC-SEC using UVA, DOC, and fluorescence detection, Water Res., 37, 42954303, 2003.

Kalbitz, K., Geyer, W., and Geyer, S.: Spectroscopic properties of dissolved humic substances - a reflection of land use history in a fen area, Biogeochemistry, 47, 219-238, 1999.

Kim, H.-C. and Yu, M.-J.: Characterization of natural organic matter in conventional water treatment processes for selection of treatment processes focused on DBPs control, Water Res., 39, 4779-4789, 2005.

Kitis, M., Karafani, T., Kilduff, J. E., and Wigton, A.: The reactivity of natural organic matter to disinfection by-products formation and its relation to specific ultraviolet absorbance, Water Sci. Technol., 43, 9-16, 2001.

Korshin, G. V., Kumke, M. U., Li, C.-W., and Frimmel, F. H.: Influence of chlorination on chromophores and fluorophores in humic substances, Environ. Sci. Technol., 33, 1207-1212, 1999.

Leenheer, J. A.: Comprehensive approach to preparative isolation and fractionation of dissolved organic carbon from natural waters and wastewaters, Environ. Sci. Technol., 15(5), 578-587, 1981.

Li, C.-W., Benjamin, M. M., and Korshin, G. V.: Use of UV spectroscopy to characterize the reaction between NOM and free chlorine, Environ. Sci. Technol., 34(12), 2370-2575, 2000.

Najm, I. N., Patania, N. L., Jacangelo, J. G., and Krasner, S. W.: Evaluating surrogates for disinfection by-products, J. Amer. Water Works Assoc., 86, 98-106, 1994.

Nguyen, M.-L., Westerhoff, P., Baker, L., et al.: Characteristics and reactivity of algae-produced dissolved organic carbon, J. Environ. Eng., 131(11), 1574-1582, 2005.

Peiris, B. R., Halle, C., Haberkamp, J., et al.: Assessing nanofiltration fouling in drinking water treatment using fluorescence fingerprinting and LC-OCD analyses, Water Sci. Technol. Water. Supp., 8, 459-465, 2008.

Reckhow, D. A., Singer, P. C., and Malcolm, R. L.: Chlorination of humic materials: byproduct formation and chemical interpretations, Environ. Sci. Technol., 24(11), 1655-1664, 1990.
Roccaro, P. and Vagliasindi, F. G.: Differential vs. absolute UV absorbance approaches in studying NOM reactivity in DBPs formation: Comparison and applicability, Water Res., 43, 744-750, 2009.

Rosario-Ortiz, F. L., Snyder, S. A., and Suffet, I. H.: Characterization of dissolved organic matter in drinking water sources impacted by multiple tributaries, Water Res., 41, 4115-4128, 2007.

Senesi, N.: Molecular and quantitative aspects of the chemistry of fulvic acid and its interaction with metal ions and organic chemicals. Part 2. The fluorescence spectroscopy approach, Analit. Chim. Acta, 232, 77-106, 1990.

Soh, Y. C., Roddick, F., and van Leeuwen, J.: The impact of alum coagulation on the character, biodegradability and disinfection by-product formation potential of reservoir natural organic matter (NOM) fractions, Water Sci. Technol., 58, 1173-1179, 2008.

Stewart, A. J. and Wetzel, R. G.: Asymmetrical relationships between absorbance, fluorescence, and dissolved organic carbon, Limnol. Oceanogr., 26, 590-597, 1980.

Świetlik, J. and Sikorska, E.: Application of fluorescence spectroscopy in the studies of natural organic matter fractions reactivity with chlorine dioxide and ozone, Water Res., 38, 3791-3799, 2004.

Wang, G.-S. and Hsieh, S.-T.: Monitoring natural organic matter in water with scanning spectrophotometer, Environ. Int., 26, 205212, 2001.

Weishaar, J. L., Aiken, G. R., Bergamaschi, B. A., et al.: Evaluation of specific ultraviolet absorbance as an indicator of the chemical composition and reactivity of dissolved organic carbon, Environ. Sci. Technol., 37(20), 4702-4708, 2003.

Wu, W. W., Chadik, P. A., Davis, W. M., et al.: The effect of structural characteristics of humic substances on disinfection byproduct formation in chlorination, in: Natural Organic Matter and Disinfection By-Products-Characterization and Control in Drinking Water: ACS Symposium Series 761, edited by: Barrett, S. E., Krasner, S. W., and Amy, G. L., American Chemical Society, Washington, D.C., 109-121, 2000.

Wu, W. W., Chadik, P. A., and Delfino, J. J.: The relationship between disinfection by-product formation and structural characteristics of humic substances in chloramination, Environ. Toxic. Chem., 22(12), 2845-2852, 2003.

Yang, X., Shang, C., Lee, W., et al.: Correlations between organic matter properties and DBP formation during chloramination, Water Res., 42, 2329-2339, 2008. 